\title{
A Case Report on Metformin and Insulin Induced Hypoglycemia
}

\author{
Dr. Hari Krishna A, Mahesh Pavan K, Upajna V and Navya Deepika B
}

Avanthi Institute of Pharmaceutical Sciences, Cherukupally, Vizianagaram, Visakhapatnam, Andhra Pradesh, India

*Corresponding author: Mahesh Pavan K, Student, Avanthi Institute of Pharmaceutical Sciences, Cherukupally, Vizianagaram, Visakhapatnam, Andhra Pradesh, India, Tel: 9494579837; E-mail: maheshpavankontheti@gmail.com

Received date: April 05, 2020; Accepted date: April 16, 2020; Published date: April 23, 2020

Citation: Hari Krishna A, Mahesh Pavan K, Upajna V, Navya Deepika B (2020) A Case Report on Metformin and Insulin Induced Hypoglycemia. Arch Med Vol: 12 Iss: 2: 6

Copyright: (2020 Hari Krishna A, et al. This is an open-access article distributed under the terms of the Creative Commons Attribution License, which permits unrestricted use, distribution, and reproduction in any medium, provided the original author and source are credited.

\section{Abstract}

Metformin is a biguanide anti-hyperglycemic drug which is the most commonly prescribed oral agent to treat diabetes mellitus. Metformin work by decreasing hepatic glucose production, decrease GI glucose absorption, increase target cell insulin sensitivity. Insulin is the hormone produced by the pancreas that controls the levels of glucose or sugar in blood. Drug-induced low blood sugar is low blood glucose that results from taking medicine. This is a case report of 78 years old male patient who was admitted in surgical ward with a chief complaint of raw area over right forearm since 30 days and now he is diagnosed as Diabetic cellulitis of right upper limb. Before the diagnosis of diabetic cellulitis the patient was on Metformin+ glibenclamide therapy. After the diagnosis, the physician prescribed metformin along with human mixtard. Surgery was done for cellulitis of right forearm and again he is prescribed with human mixtrad for 10 days due to which FBS levels dropped. On 11th of post- surgical treatment, he is prescribed with metformin and Injection. Insulin and as a result FBS levels reached less than normal range. We conclude that ADR might have been possible with same dynamic activity medication duplication therapy of insulin and human mixtard and also due to the combination therapy of metformin and insulin. We should monitor the prescription always with drug relevant problems (DRP's) to avoid drug induced complications in a patient.

Keywords: Hypoglycemia; Metformin; Insulin; Adverse drug reaction

\section{Introduction}

\section{Diabetes mellitus}

Diabetes mellitus is a complex chronic illness associated with a state of high blood glucose level or hyperglycemia occurring from deficiencies in insulin secretion, action or both. The clinical diagnosis of diabetes is based on either one of the four plasma glucose criteria. (I) elevated fasting plasma glucose (>126 mg/dl) (II) $2 \mathrm{~h}$ PG during $75 \mathrm{~g}$ oral glucose tolerance test $(<200 \mathrm{mg} / \mathrm{dl})$, (III) Random plasma glucose $(<200$ $\mathrm{mg} / \mathrm{dl}$ ) with classic signs and symptoms of hyperglycemia or (IV) Haemoglobin A1C level more than 6.5\% [1].

\section{Metformin}

Metformin is a biguanide anti-hyperglycemic drug which is the most commonly prescribed oral agent to treat diabetes mellitus [2].

\section{Insulin}

Insulin is the hormone produced by the pancreas that controls the levels of glucose or sugar in blood. When the body digests carbohydrates, it breaks them down into sugar molecules. Glucose is one of these. Glucose is absorbed directly into the blood stream, but it needs the help of insulin to get into cell and tissues to provide them with fuel [3].

\section{Drug induced hypoglycemia}

It is a significant adverse effect that should be included in the differential diagnosis of hypoglycemia that results from taking a medicine [4]. Causes for drug induced hypoglycemia include alcohol consumption, getting more activity than usual, intentionally or unintentionally overdosing on the medicines used to treat diabetes, missing meals. Metformin in combination with sulfonylureas, insulin [5].

\section{Case Report}

A male patient of 78 years old was admitted in male surgical ward in King George Hospital, Visakhapatnam with a chief complaint of raw area over right forearm since 30 days. Raw area is preceded by formation of a papule which enlarged rapidly into the entire forearm associated with pain. He is suffering from diabetes mellitus and is on antidiabetic medication Tablet Metformin+Glibenclamide. He was prescribed with Injection Human mixtard, Tablet Metformin, Injection Piperacillin+tazobactum, Tablet Paracetamol, Tablet B complex, Injection Tramadol, Tablet Amoxicillin+clavulanate, 
Tablet Griseofulvin, Tablet Iron, Tablet Ofloxacin for 10 days. Surgery was done for cellulitis of right forearm. After surgery, he was prescribed with Injection Cefperazone+sulbactum, Injection Metronidazole, Injection Paracetamol, Injection Pantoprazole, Injection Tramadol, Injection Ondansetron,
Injection Human mixtard, Tablet Iron+ folic acid, Tablet B complex and Injection Piperacillin+tazobactum for 10 days. On 11th day he was prescribed with Injection. Insulin and Tablet Metformin (Table 1).

Table 1 Medicines prescribed during the surgery.

\begin{tabular}{|l|l|l|l|l|l|}
\hline Day of Treatment & Day $\mathbf{1}$ & Day $\mathbf{5}$ & Day $\mathbf{8}$ & Day $\mathbf{9}$ & Day $\mathbf{1 0}$ \\
\hline Fasting Blood Glucose & $131 \mathrm{mg} / \mathrm{dl}$ & $131 \mathrm{mg} / \mathrm{dl}$ & $71 \mathrm{md} / \mathrm{dl}$ & $71 \mathrm{mg} / \mathrm{dl}$ & $82 \mathrm{mg} / \mathrm{dl}$ \\
\hline
\end{tabular}

\section{Laboratory data include haemoglobin}

$9 \mathrm{~g} / \mathrm{dl}$, PCV: 26\%, platelets: 1.5 lakhs/cumm, neutrophils: $70 \%$, lymphocytes: $26 \%$, eosinophils: $4 \%$, total bilirubin: 0.3 , direct bilirubin: 0.1 , indirect bilirubin: 0.2 , ESR: $40 \mathrm{~mm} / 1 \mathrm{st}$ hour, T3: 0.50, T4: 6.84, TSH: 4.47, urea: $35 \mathrm{mg} / \mathrm{dl}$, serum creatinine: $1.0 \mathrm{mg} / \mathrm{dl}$, alkaline phosphatase: $91 \mathrm{U} / \mathrm{L}$, SGPT: 73 U/L, SGOT: $22 \mathrm{U} / \mathrm{L}$, serum sodium: $134 \mathrm{meq} / \mathrm{l}$, serum potassium: $4.82 \mathrm{meq} / \mathrm{l}$, serum chloride: $100 \mathrm{meq} / \mathrm{l}$.

\section{ADR history}

Patient was administered with Injection Human mixtard from $2 / 10 / 2019$ to $11 / 10 / 2019$. During these days the fasting blood glucose levels dropped to levels less than normal. But again the patient was administered with Tablet Metformin and injection Insulin on $12 / 10 / 2019$. Patient experienced further hypoglycemic condition and the fasting blood glucose levels dropped to $56 \mathrm{mg} / \mathrm{dl}$. After 12 days the patient was discharged against medical advices. We suspect that the ADR occurred due to metformin and insulin as per analysis of Hartwig severity assessment scale and WHO-causality assessment scale.

\section{ADR management}

ADR management includes withdrawal or suspension, dose reduction of suspected drug and administration of supportive therapy. In this case the suspected drugs were not discontinued.

\section{ADR analysis}

ADR analysis results are given in Table 2.

Table 2 ADR analysis.

\begin{tabular}{|l|l|c|}
\hline Suspected drug and reactions & Hartwig severity assessment scale & WHO-causality assessment scale \\
\hline Metformin induced hypoglycemia & Moderate level-3 & Probable \\
\hline
\end{tabular}

\section{Clinical pharmacist prescription evaluation}

The prescription had a duplication therapy involving Injection Human mixtard and Injection Insulin and also drug induced hypoglycemia may occur due to the combination therapy of metformin and insulin. So we suspect that ADR has occurred because of these reasons.

\section{Discussion}

Combination of metformin and insulin are used to treat diabetes mellitus. But there is risk of occurrence of hypoglycemic condition in such case [6]. While comparing our work with Combination of Insulin and Metformin in the Treatment of Type 2 Diabetes, a case report by Wulffel et al. [6] we observed that the risk of increased hypoglycemic condition was more while administering the combination of metformin and insulin when compared to insulin alone.

\section{Conclusion}

Metformin and insulin are commonly prescribed drugs to treat diabetes mellitus. Physician must suspect if such reaction occurs during therapy involving metformin and insulin and should carefully evaluate drug associated adverse reactions. It is important that these reactions are identified and documented in the patient record and patient should be explained properly not to use that drug so that their recurrence can be avoided in future and close monitoring of patients is very important and prescription must be analyzed carefully. This will assure us to give safest and effective therapy with best economic cost and length of hospital stay would also be reduced.

\section{References}

1. Chaudhury A, Duvoor C, Dendi R, Sena V, Kraleti S, et al. (2017) Clinical review of anti-diabetic drugs: Implications for type 2 diabetes mellitus management. Front Endocrinol 8: 6.

2. Suchard JR, Grotsky TA (2008) Fatal metformin overdose presenting with progressive hyperglycemia. West J Emerg Med 9: 160-164.

3. Debra Manzella RN, Michael Menna DO (2019) Causes and risk factors of hyperglycemia (High Blood Glucose).

4. Murad MH, Coto-Yglesias F, Wang AT, Sheidaee N, Mullan RJ, et al. (2009) Drug-induced hypoglycemia: A systematic review. J Clin Endocrinol Metab. 94: 741-745. 
5. https: //www.nlm.nih.gov/
6. Wulffelé MG, Kooy A, Lehert $P$, Bets $D$, Ogterop JC, et al. (2002) Combination of insulin and metformin in the treatment of type 2 diabetes. Diabetes care. 25: 2133-2140. 